\title{
Endothelin-1 promotes vascular smooth muscle cell migration across the artery wall: a mechanism contributing to vascular remodelling and intimal hyperplasia in giant-cell arteritis
}

Ester Planas-Rigol, ${ }^{1}$ Nekane Terrades-Garcia, ${ }^{1}$ Marc Corbera-Bellalta, ${ }^{1}$ Ester Lozano, Marco A Alba, ${ }^{1}$ Marta Segarra, ${ }^{1}$ Georgina Espígol-Frigolé, ${ }^{1}$ Sergio Prieto-González, ${ }^{1}$ José Hernández-Rodríguez, ${ }^{1}$ Sara Preciado, ${ }^{2}$ Rodolfo Lavilla, ${ }^{2}$ Maria C Cid ${ }^{1}$

${ }^{1}$ Vasculitis Research Unit, Department of Autoimmune Diseases, Hospital Clinic, University of Barcelona, Institut d'Investigacions Biomèdiques August Pi i Sunyer (IDIBAPS),

CRB-CELLEX, Barcelona, Spain ${ }^{2}$ Laboratory of Organic Chemistry, Faculty of Pharmacy, University of Barcelona and CIBER-BBN, Networking Centre on Bioengineering, Biomaterials and Nanomedicine, Barcelona Science Park, Barcelona, Spain

\section{Correspondence to}

Dr Maria C Cid, Department of Autoimmune Diseases, Hospital Clínic, Villarroel, 170, 08036-Barcelona, Spain; mccid@clinic.ub.es

Received 8 November 2016 Revised 12 May 2017 Accepted 17 May 2017
CrossMark

To cite: Planas-Rigol $\mathrm{E}$, Terrades-Garcia N, CorberaBellalta $\mathrm{M}$, et al. Ann Rheum Dis Published Online First: [please include Day Month Year]. doi:10.1136/ annrheumdis-2016-210792

\section{ABSTRACT}

Background Giant-cell arteritis (GCA) is an inflammatory disease of large/medium-sized arteries, frequently involving the temporal arteries (TA). Inflammation-induced vascular remodelling leads to vaso-occlusive events. Circulating endothelin-1 (ET1 ) is increased in patients with GCA with ischaemic complications suggesting a role for ET-1 in vascular occlusion beyond its vasoactive function.

Objective To investigate whether ET-1 induces a migratory myofibroblastic phenotype in human TAderived vascular smooth muscle cells (VSMC) leading to intimal hyperplasia and vascular occlusion in GCA. Methods and results Immunofluorescence/confocal microscopy showed increased ET-1 expression in GCA lesions compared with control arteries. In inflamed arteries, ET-1 was predominantly expressed by infiltrating mononuclear cells whereas ET receptors, particularly ET-1 receptor $B\left(E T_{B} R\right)$, were expressed by both mononuclear cells and VSMC. ET-1 increased TA-derived VSMC migration in vitro and $\alpha$-smooth muscle actin ( $\alpha S M A)$ expression and migration from the media to the intima in cultured TA explants. ET-1 promoted VSMC motility by increasing activation of focal adhesion kinase (FAK), a crucial molecule in the turnover of focal adhesions during cell migration. FAK activation resulted in Y397 autophosphorylation creating binding sites for SrC kinases and the p85 subunit of PI3kinases which, upon ET-1 exposure, colocalised with FAK at the focal adhesions of migrating VSMC. Accordingly, FAK or PI3K inhibition abrogated ET-1-induced migration in vitro. Consistently, ET-1 receptor $A$ and $\mathrm{ET}_{B} \mathrm{R}$ antagonists reduced $\alpha S M A$ expression and delayed VSMC outgrowth from cultured GCA-involved artery explants.

Conclusions ET- 1 is upregulated in GCA lesions and, by promoting VSMC migration towards the intimal layer, may contribute to intimal hyperplasia and vascular occlusion in GCA.

\section{INTRODUCTION}

Giant-cell arteritis (GCA) is a granulomatous vasculitis targeting large and medium-sized arteries in aged individuals. ${ }^{12}$ Inflammation-induced vascular remodelling results in intimal hyperplasia leading to symptoms of vascular insufficiency or irreversible ischaemic complications in $20 \%-30 \%$ of patients. ${ }^{3-6}$
It is generally assumed that vascular smooth muscle cells (VSMC) migrate through disrupted elastic fibres towards the intima where they produce abundant matrix proteins. ${ }^{6}$ However, underlying mechanisms remain virtually unexplored. Several growth factors, including PDGF, TGF $\beta$, EGF, NGF or BDNF, are expressed in GCA lesions and may participate in this process based on their ability to stimulate proliferation and/or migration of VSMC in vitro. ${ }^{78}$

Visual loss, the most frequent ischaemic complication in GCA, is frequently preceded by transient episodes of blindness (amaurosis fugax) suggesting that reversible vasospasm may initially contribute to flow reduction in small arteries supplying the optic nerve. ${ }^{3-5}$ Endothelin-1 (ET-1) is a potent vasoactive peptide that might potentially participate in this process. ${ }^{9}{ }^{10}$ ET-1 is mainly synthesised by endothelial cells although VSMC and macrophages may also produce it. $^{9}{ }^{11}$ ET-1 signals through two G-protein coupled receptors (GPCR): E-1 receptors A and B $\left(E_{A} R\right.$ and $\left.E_{B} R\right)$. Both $E_{A} R$ and $E_{B} R$ mediate VSMC contraction. Signalling through $\mathrm{ET}_{\mathrm{B}} \mathrm{R}$ on endothelial cells may also produce vasodilatation by stimulating nitric oxide and prostacyclin production. . $^{10} 12$

Although the majority of previous studies on ET-1 functions have focused on VSMC regulation of the vascular tone, in recent years, skin, liver and lung fibroblasts have been identified as important targets of ET-1. ${ }^{13} 14$ ET-1 promotes myofibroblast differentiation of fibroblasts, a crucial step in the development of fibrogenic diseases such as systemic sclerosis and cardiac, pulmonary or hepatic fibrosis. ${ }^{13-15}$

The inflammatory milieu of GCA is enriched in cytokines and growth factors able to enhance ET-1 expression such as TGF $\beta$ among others. ${ }^{9} 16$ We and others have recently shown that ET-1, ET $\mathrm{R}$ and $\mathrm{ET}_{\mathrm{B}} \mathrm{R}$ are increased in GCA lesions, although the specific cells expressing the ET-1 system components have not been determined. ${ }^{17}{ }^{18}$ In spite of the short half-life of circulating ET-1, plasma ET-1 concentrations are elevated in patients with GCA-related cranial ischaemic complications. ${ }^{18}$

Since arteries involved by GCA are usually larger than resistance arteries controlling vascular tone, we hypothesised that, in addition to its vasoactive function, ET-1 might contribute to the development of intimal hyperplasia by stimulating a myofibroblast 
phenotype in VSMC and promoting their migration towards the intimal layer. Consequently, we investigated the effect of ET-1 on human temporal artery (TA)-derived VSMC migration in vitro and ex vivo as well as the signalling pathways involved.

\section{METHODS}

\section{Patient samples}

TA biopsies were performed to 10 patients with suspected GCA (see online supplementary table S1). Five biopsies disclosed typical GCA histopathological features and were used in the indicated experiments. The remaining five showed no inflammatory lesions and served as controls. Patients with negative biopsies were eventually diagnosed with other conditions (see online supplementary table S2). The study was approved by the local Ethics Committee (Hospital Clinic of Barcelona) and patients signed informed consent.

\section{Isolation and culture of VSMC derived from human TA}

Human TA-derived VSMCs were obtained from explanted TA sections from the above patients cultured on Matrigel and characterised by flow cytometry, as described. ${ }^{718} 19$ In specific experiments, VSMCs were cocultured with peripheral blood mononuclear cells (PBMC) or purified subsets (CD4+ T cells or CD14+ monocytes) (online supplementary methods).

\section{Reagents}

See online supplementary methods.

\section{Immunofluorescence}

Immunofluorescence staining was performed in cultured VSMC or in fresh-frozen or cultured TA sections. Antibodies used, dilutions and detailed steps are depicted in online supplementary methods.

\section{Quantitative real-time reverse transcription PCR}

RNA was extracted from cultured VSMC using TRIzol Reagent (Life Technologies, Paisley, UK). Prepro-ET-1 and $\alpha$-smooth muscle actin ( $\alpha \mathrm{SMA})$ mRNAs $(1 \mu \mathrm{g})$ were measured by quantitative reverse transcription PCR with specific TaqMan gene expression assays from Applied Biosystems as reported. ${ }^{18}$

\section{ET-1 immunoassay}

ET-1 in cell supernatants was measured using R\&D Quantikine ELISA Kit.

\section{Migration assay}

VSMC migration was assessed using Boyden chambers with $10 \mu \mathrm{m}$ pore polyester filters. Further details are exposed in the online supplementary methods.

\section{Scratch wound-healing assay}

VSMCs were seeded at $80 \%$ confluence onto $0.1 \%$ gelatin-precoated 12-well plates and cultured overnight. One scratch per well was done before adding fresh Dulbecco's modified Eagle medium supplemented with $50 \mathrm{mmol} / \mathrm{L}$ of HEPES (Sigma-Aldrich) and BQ123, BQ788 $(20 \mu \mathrm{mol} / \mathrm{L})$ or combination of both inhibitors. ET-1 $\left(10^{-9} \mathrm{~mol} / \mathrm{L}\right)$ or fresh medium was added to each corresponding well. Time-lapse video microscopy was applied to record cell movement and results were analysed as depicted in online supplementary methods. A proliferation assay was also performed to assess the potential impact of ET-1 on cell growth (see online supplementary figure S1).

\section{Western blot and gelatin zymography}

See details in online supplementary methods. ${ }^{20} 21$

\section{Transient transfection}

Focal adhesion kinase (FAK) wild-type cDNA and FAK point mutants Y397F and Y925F, cloned into the pCDNA3 expression vector, were kindly provided by Kazue Matsumoto and Kenneth M Yamada (National Institute of Dental and Craniofacial Research, National Institutes of Health, Bethesda, Maryland) and generated as previously described. ${ }^{20} 22$ Lipofectamine 2000 Reagent (Invitrogen) was used for transient transfection of VSMC. Transfection efficiency was about 30\% (see online supplementary figure S2).

\section{Ex vivo-cultured TA sections from patients with GCA}

TA sections from four treatment-naive patients with GCA and four controls were cultured on Matrigel as described, ${ }^{19}{ }^{23}$ with or without BQ123 or BQ788 $(20 \mu \mathrm{mol} / \mathrm{L})$. VSMC outgrowth was scored in three arteries at various time points by two investigators (EPR and $\mathrm{MCB}$ ) blinded to the conditions tested.

\section{Statistical analysis}

Mann-Whitney U test for independent variables was applied using SPSS software, PASW V.22.0.

\section{RESULTS}

\section{Distribution of the ET-1 system in GCA lesions compared with} controls

In control arteries, slight ET-1 expression was observed in organised VSMC in the media and in the luminal endothelium (figure 1A). In GCA-involved arteries, ET-1 was intensively expressed by clusters of infiltrating inflammatory cells (figure $1 \mathrm{~B}, \mathrm{~b} .1$ and figure $1 \mathrm{C}$, c.1) and by scattered remaining VSMC (figure 1B, b.2). In addition, ET-1 expression by the luminal endothelium was increased (figure 1B,C) compared with control arteries (figure 1A).

To further characterise the cell types responsible for ET-1 production in GCA, primary cultures of VSMC were obtained from normal $\mathrm{TA}$ and cocultured with purified CD4+ T lymphocytes or monocytes $(\mathrm{CD} 14+)$ from healthy donors in order to mimic vascular inflammation. ${ }^{24}$ Interestingly, a slight but consistent increase in prepro-ET-1 mRNA expression was observed in CD4+ T lymphocytes and to a lesser extent in CD14+ monocytes, when cocultured with VSMC (figure 1D). VSMC remarkably expressed and secreted mature ET-1 (figure 1E). When in coculture, unprocessed big ET-1 increased in PBMC and decreased in VSMC lysates. Overall, secreted ET-1, mainly produced by VSMC, decreased in coculture supernatants (figure $1 \mathrm{~F}$ ). The increase in prepro-ET-1 mRNA in PBMC cocultured with VSMC was confirmed in three paired experiments performed with PBMC and VSMC from the same GCA donor (figure 1G).

Expression of $\mathrm{ET}_{\mathrm{A}} \mathrm{R}$ and $\mathrm{ET}_{\mathrm{B}} \mathrm{R}$ was explored in the same TA specimens. In control arteries, $\mathrm{ET}_{\mathrm{A}} \mathrm{R}$ was expressed by VSMC in the media whereas $\mathrm{ET}_{\mathrm{B}} \mathrm{R}$ was hardly detected (figure $1 \mathrm{H}, \mathrm{I}$ ). In GCA, both $\mathrm{ET}_{\mathrm{A}} \mathrm{R}$ and $\mathrm{ET}_{\mathrm{B}} \mathrm{R}$ receptors were expressed by $\alpha$ SMA-positive cells at the intima-media border (figure $1 \mathrm{~J}, \mathrm{~K}$ ). Endothelial cells and inflammatory cells also expressed both ET receptors (figure $1 \mathrm{~J}, \mathrm{~K}$ ).

\section{ET-1 promotes VSMC cytoskeleton reorganisation and migration through $\mathrm{ET}_{\mathrm{A}} \mathrm{R}$ and $\mathrm{ET}_{\mathrm{B}} \mathrm{R}$}

To investigate whether ET-1 promoted a myofibroblast phenotype in VSMC, we explored changes in cytoskeleton organisation induced by ET-1 in cultured TA-derived VSMC. ET-1 elicited 

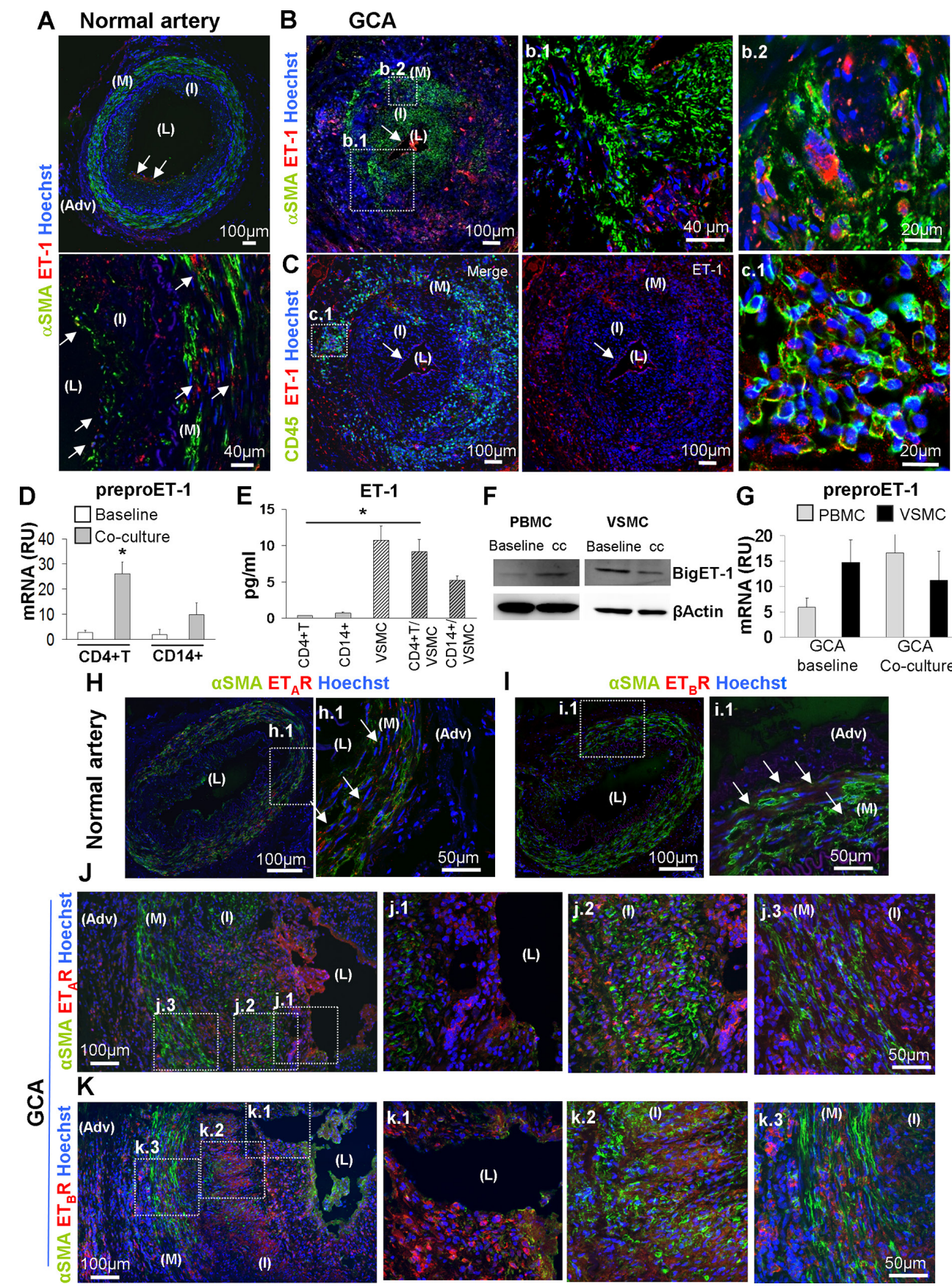

Figure $1 \mathrm{ET}-1, \mathrm{ET}_{\mathrm{A}} \mathrm{R}$ and $\mathrm{ET}_{\mathrm{B}} \mathrm{R}$ expression in GCA lesions compared with control TA. (A) Immunostaining of ET-1 (red), $\alpha \mathrm{SMA}$ (green) and nuclei (blue) in a control TA. (B) Immunostaining of ET-1 (red), $\alpha$ SMA (green) and nuclei (blue) in a TA with typical GCA involvement. White arrow highlights ET-1 expression by the endothelium. (b.1 and b.2) Magnifications of 1B showing independent expression or coexpression of $\alpha$ SMA and ET-1, respectively. (C) Immunostaining of ET-1 (red), CD45 (green) and nuclei (blue) in a GCA-involved TA. (c.1) Magnification of 1C showing CD45+ cells expressing ET-1. ET-1 distribution was confirmed in three different GCA and control arteries. L, lumen; I, intima; M, media; Adv, adventitia. (D) PreproET-1 mRNA expression by purified CD4+ T cells or CD14+ monocytes isolated or cocultured with VSMC for 24 hours. Bars represent mean and SEM of triplicates. * $p<0.05$ cocultured versus isolated. (E) Immunoassay of supernatants from isolated CD4+ T lymphocytes, CD14+ monocytes or VSMC, or supernatants from cocultures of CD4+ T cells or CD14+ monocytes with VSMC for 24 hours. Bars represent mean and SEM of triplicates. ${ }^{*} p<0.05$ cocultured versus isolated. (F) Big-ET-1 detection by western blot in lysates $(20 \mu \mathrm{g} / \mathrm{lane})$ of isolated PBMC or PBMC cocultured with VSMC, and in lysates of VSMC isolated or cocultured with PBMC for 24 hours. (G) Prepro-ET-1 mRNA expression by PBMC from three patients with GCA and their corresponding VSMC isolated or in coculture for 24 hours. $(H, I)$ Immunofluorescence staining of $E_{A} R$ (red) or $E T_{B} R$ (red) together with $\alpha S M A$ (green) and nuclei (blue) in a control TA and their corresponding magnifications (h.1, i.1). (J, K) Immunofluorescence staining of $E T_{A} R$ (red) or $E T_{B} R$ (red) together with $\alpha$ SMA (green) and nuclei (blue) in a GCA-involved TA and their corresponding magnifications of the endothelium (j.1, $k .1$ ), neointima $(j .2, k .2)$ and media (j.3, k.3). $\alpha$ SMA, $\alpha$-smooth muscle actin; ET-1, endothelin-1; ET $R$, ET-1 receptor A; ET $R$ R, ET-1 receptor B; GCA, giant-cell arteritis; $\mathrm{RU}$, relative units; PBMC, peripheral blood mononuclear cells; TA, temporal arteries; VSMC, vascular smooth muscle cells. 
A Hoechst Phalloidin
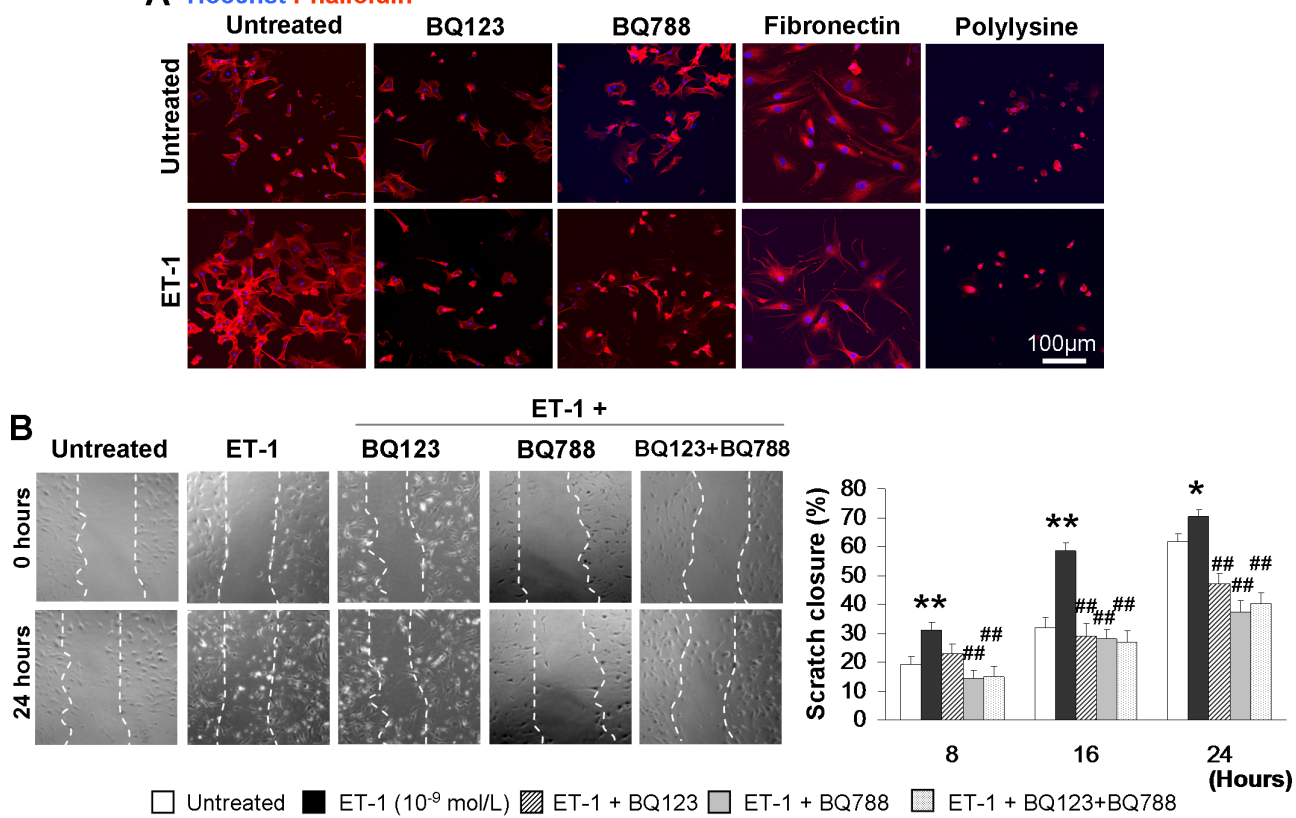

C

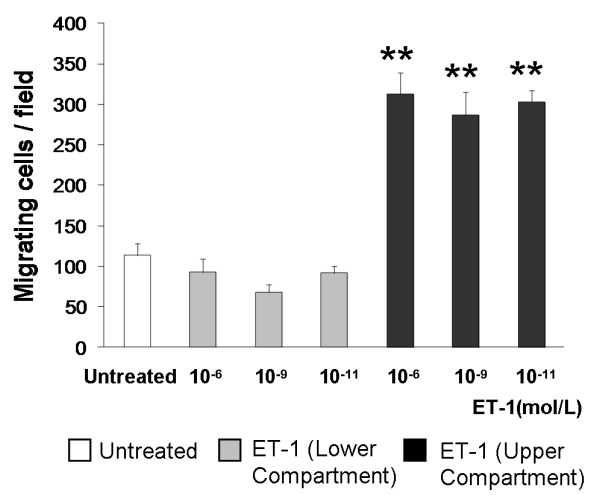

D

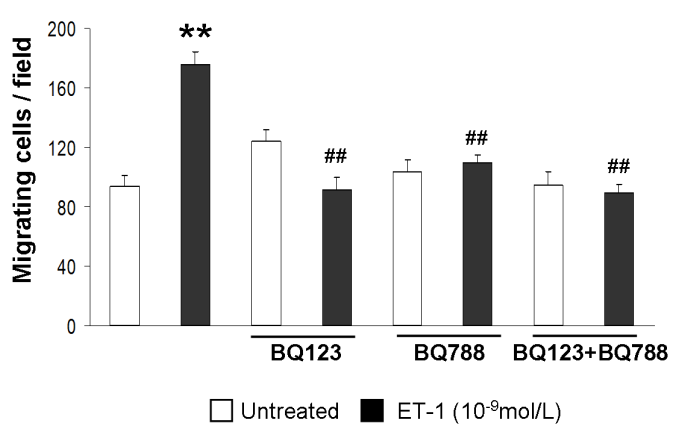

Figure 2 Effect of ET-1 on TA-derived VSMC cytoskeleton reorganisation and migration. (A) Immunofluorescence of VSMC f-actin with phalloidinrhodamine (red) and nuclei (blue). VSMCs were preincubated with $\mathrm{ET}_{\mathrm{A}} \mathrm{R}$ antagonist $\mathrm{BQ} 123(20 \mu \mathrm{mol} / \mathrm{L}), \mathrm{ET}_{\mathrm{B}} \mathrm{R}$ antagonist BQ788 $(20 \mu \mathrm{mol} / \mathrm{L})$ or both in suspension for $45 \mathrm{~min}$. ET-1 $\left(10^{-9} \mathrm{~mol} / \mathrm{L}\right)$ was added at the time of VSMC seeding on plastic, fibronectin $\left(5 \mu \mathrm{g} / \mathrm{cm}^{2}\right)$ or polylysine $(10 \mu \mathrm{g} / \mathrm{mL})$ and VSMCs were incubated for 3 hours before fixing and staining. (B) Scratch wound healing assay of VSMC untreated or exposed to ET-1 $\left(10^{-9} \mathrm{~mol} / \mathrm{L}\right)$, with or without the presence of BQ123 $(20 \mu \mathrm{mol} / \mathrm{L}), \mathrm{BQ} 788(20 \mu \mathrm{mol} / \mathrm{L})$ or both. Graph represents percentage of scratch closure over time in three independent experiments. (C) Boyden chamber migration assay. ET-1 was added either to the lower or in the upper compartment at the indicated concentrations. Cells were counted at $4 \times$ magnification. ${ }^{* *} p<0.005$ for untreated cells versus ET-1-treated cells. Bars represent number of cells (mean and SEM of quadruplicates). (D) Boyden chamber migration assay where ET-1 was added to the upper compartment with or without preincubation with antagonists BQ123, BQ788 or both. Cells were counted at 10x magnification. Bars represent number of cells (mean and SEM of quadruplicates). $(B, D){ }^{*} p<0.05 /{ }^{* *} p<0.005$ for untreated cells versus ET-1-treated cells. \#p $<0.05 / \# \# p<0.005$ comparing ET-1-treated cells versus cells incubated with ET-1 receptor antagonists BQ123 or BQ788. ET-1, endothelin-1; $\mathrm{ET}_{\mathrm{A}} \mathrm{R}, \mathrm{ET}-1$ receptor $\mathrm{A} ; \mathrm{ET}_{\mathrm{B}} \mathrm{R}$, ET-1 receptor $\mathrm{B} ; \mathrm{TA}$, temporal arteries; VSMC, vascular smooth muscle cells.

spreading of VSMC with a striking formation of cytoplasm protrusions (figure 2A). Cell spreading was not induced in VSMC cultured on polylysine and was more remarkable when VSMCs were cultured on fibronectin (figure 2A), suggesting participation of integrin-mediated signalling pathways in this process. ${ }^{25}$ Spreading was reverted by blocking ET-1 signalling with $\mathrm{ET}_{\mathrm{A}} \mathrm{R}$ antagonist $\mathrm{BQ} 123$ and $\mathrm{ET}_{\mathrm{B}} \mathrm{R}$ antagonist $\mathrm{BQ} 788$ (figure $2 \mathrm{~A}$ ).

ET-1-induced VSMC morphology changes were associated with increased migratory activity (see online supplementary movie). ET-1 exposure resulted in significantly faster scratchwound closure (figure $2 \mathrm{~B})$. $\mathrm{ET}_{\mathrm{A}} \mathrm{R}$ and $\mathrm{ET}_{\mathrm{B}} \mathrm{R}$ antagonists (BQ123 and $\mathrm{BQ788}$, respectively) and combination of both inhibitors significantly abrogated ET-1-induced VSMC migration, indicating implication of both receptors in this process (figure $2 \mathrm{~B}$ ). ET-1 did not accelerate scratch-wound closure by stimulating VSMC growth, since no significant increase in VSMC proliferation was elicited by ET-1 (online supplementary figure S1).

ET-1 induced VSMC migration in Boyden chambers when added to the upper compartment (figure 2C). In contrast, when ET-1 was added to the lower compartment, no differences in migration were observed, indicating that ET-1 has no chemoattractant activity and primarily stimulates motility (figure 2C). ET-1-induced migration was abrogated by BQ788 and BQ123 or the combination of both (figure 2D). 


\section{FAK phosphorylation at Y397 is essential for ET-1 induction of VSMC migration}

Based on the relevance of integrin engagement in ET-1-induced cytoskeleton reorganisation, and the seminal role of FAK in integrin-mediated cell motility, we explored the involvement of FAK in ET-induced VSMC migration. FAK is a docking and signalling tyrosine kinase with a seminal role in focal adhesion turnover required for cell migration in response to integrin binding or growth factor signalling. ${ }^{25-27}$

FAK activation results in autophosphorylation of crucial tyrosine residues. ${ }^{25-27}$ One of the best characterised is Y397 which provides a binding site for Src-type tyrosine kinases promoting their recruitment to focal adhesions and allowing their phosphorylation. This interaction is essential for cell migration in fibroblasts and malignant cells. ${ }^{26-29}$ Src, in turn, phosphorylates additional tyrosine residues, including Y925, located within the focal adhesion targeting sequence at the FAK C-terminal domain. ${ }^{30}$ Phosphorylated Y925 may recruit the adaptor protein Grb2, leading to activation of the GTP-binding protein Ras, and to ERK1/2 activation. ${ }^{30}$

ET-1 increased phosphorylation of Y397 and Y925 FAK residues (figure $3 \mathrm{~A}$ ), particularly when cells were cultured on plastic or fibronectin whereas this effect was absent in cells plated on polylysine (figure $3 \mathrm{~A}, \mathrm{~B}$ ). FAK phosphorylation was reduced by $\mathrm{ET}_{\mathrm{A}} \mathrm{R}$ or $\mathrm{ET}_{\mathrm{B}} \mathrm{R}$ antagonists $\mathrm{BQ} 123$ and $\mathrm{BQ788}$ (figure $3 \mathrm{~A}$ ). As G-coupled receptors, ET-1 receptors may activate heterotrimeric $G$ proteins which have important roles in integrin inside-out and outside-in signalling. ${ }^{31}$ Pertussis toxin induces ADP-ribosylation of several $\mathrm{G} \alpha_{i}$ subunits inhibiting their activity. ${ }^{32}$ As shown in figure $3 \mathrm{C}$, ET-1-induced Y397 FAK phosphorylation was abrogated by pertussis toxin confirming the participation of heterotrimeric $G$ proteins in ET-1-induced FAK activation.

To confirm the role of FAK in ET-1-induced VSMC migration, we investigated the effect of PF-573228, an inhibitor of FAK kinase activity. At concentrations able to inhibit FAK phosphorylation (see online supplementary figure S3), PF-573228 significantly decreased ET-1-induced VSMC cytoskeleton organisation and migration in a dose-dependent manner (figure 3D,E). Interestingly, at low concentrations, PF-573228 inhibited ET-1-induced migration whereas at higher concentrations it was also able to reduce baseline VSMC migration.

Consistent with a seminal role of FAK in mediating ET-1-induced migration, transient transfection of VSMC with FAK wild type significantly increased VSMC migration through Boyden chambers overcoming the effect of ET-1 which was not able to increase migration in FAK-overexpressing cells. However, transient transfection with an expression vector containing FAK Y397F point mutation abrogated ET-1-induced motility. In spite that ET-1 also increased Y925 phosphorylation, transfection of Y925F point mutant had no impact on ET-1-induced migration (figure 3F). These results indicate the crucial participation of FAK Y397 in ET-1-mediated migration in primary TA-derived VSMC.

It has been previously reported that integrin engagement and FAK signalling trigger rapid secretion of gelatinases MMP9 and MMP2 by lymphoid cells. ${ }^{20} 33$ Based on the important role of ET-1 in inducing FAK activation, we explored whether ET-1 modulated secretion of gelatinases by VSMC. ET-1 slightly increased secretion of pro-MMP2 (figure $3 \mathrm{G}$ ) and this effect was reduced by BQ788 (ET $\mathrm{R}$ antagonist) (figure $3 \mathrm{H}$ ).

ET-1 induced FAK phosphorylation and recruitment of phosphorylated FAK at the focal adhesions in the leading and rear edges and colocalisation with $\alpha$ SMA (figure 4A,B).
To confirm the relevance of the above results in GCA, cultured TA sections from patients with GCA were assessed for FAK phosphorylation. As shown in figure 4C,D, Y397-phosphorylated FAK was detected in GCA lesions, particularly at the intima and intima/media junction and FAK phosphorylation decreased upon exposure to $\mathrm{ET}_{\mathrm{A}} \mathrm{R}$ and $\mathrm{ET}_{\mathrm{B}} \mathrm{R}$ antagonists.

\section{Src and PI3kinases mediate ET-1-induced VSMC migration}

Considering the relevance of FAK Y397 in ET-1-induced VSMC migration, we next explored FAK downstream pathways involved in cell migration including ERK, Src and PI3K. ${ }^{26-30}$ ET-1 promoted Src activation revealed by increased phosphorylation of the Y416 Src residue and this was inhibited by both $\mathrm{ET}_{\mathrm{A}} \mathrm{R}$ and $\mathrm{ET}_{\mathrm{B}} \mathrm{R}$ antagonists (figure $5 \mathrm{~A}$ ).

ERK1/2 activation has a crucial role in cell motility, by phosphorylating myosin light chains and as scaffolding molecule. $^{262734}$ Although transfection with Y925F point mutant did not substantially reduce ET-1-induced migration, ET-1 increased ERK1/2 phosphorylation and this was reduced by ET-1 receptor antagonists (figure 5A), consistent with the existence of alternative ERK activating mechanisms dependent and independent of FAK. ${ }^{2630}$ Although the effect of ET-1 on baseline-activated Src and ERK phosphorylation was modest, it was consistently observed.

In accordance with the crucial role of Src in cell migration, Src inhibitor PP2 reduced baseline and ET-1-induced VSMC migration. Interestingly, PI3kinase inhibition with LY294002 selectively reduced ET-1-increased migration (figure 5B). ERK inhibition of ET-1-induced migration could not be assessed with PD98059 due to the decreased viability observed after the 6-hour exposure required for migration experiments (see online supplementary figure S4). Short-term exposure to Src and ERK inhibitors, not reducing cell viability, virtually impeded cell spreading (figure 5C) whereas PI3kinase inhibition only reduced the increase in cell protrusions induced by ET-1 (figure 5C,D).

FAK Y397 interaction with p85, the regulatory subunit of PI3kinase, is crucial to cell migration in other experimental contexts. ${ }^{35} 36$ ET-1 promoted colocalisation of PI3kinase $\mathrm{p} 85$ with FAK at VSMC focal adhesions (figure 5D). This interaction was abrogated by both $\mathrm{ET}_{\mathrm{A}} \mathrm{R}$ and $\mathrm{ET}_{\mathrm{B}} \mathrm{R}$ antagonists and by inhibition of FAK kinase activity. Inhibition of PI3kinase by LY294002 prevented formation of fully developed cell protrusions induced by ET-1, but did not prevent ET-1-induced recruitment of p85 and FAK at the focal contacts in nascent, immature buds (figure 5D).

\section{ET-1 induces neointima formation in ex vivo-cultured normal TA}

In control arteries, $\alpha S M A$-expressing quiescent VSMCs were concentrically organised (figure 6A). In contrast, in GCA-involved arteries the muscular layer was disrupted and $\alpha$ SMA-expressing VSMCs were mostly located at the neointima (figure 6A). Treatment of cultured TA explants with ET-1 at concentrations similar to those found in patient plasma ${ }^{18}$ or in the coculture supernatants increased $\alpha \mathrm{SMA}$ expression (figure 6B,C). Exposure of cultured normal TA to ET-1 also resulted in a striking disruption of the muscular layer and migration of VSMC towards the intima (figure 6B).

\section{$E T_{A} R$ and $E_{B} R$ antagonists reduce $\alpha S M A$ expression and VSMC outgrowth from ex vivo-cultured arteries from patients with GCA}

ET-receptor antagonists BQ123 and BQ788 dramatically reduced $\alpha \mathrm{SMA}$ expression in cultured artery sections for a patient with 


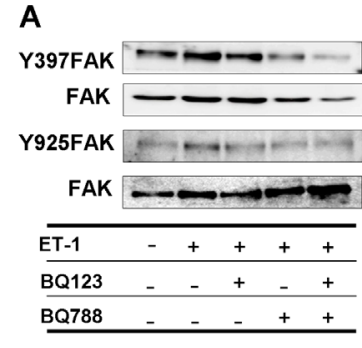

D

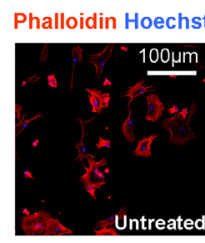

$\mathbf{F}$

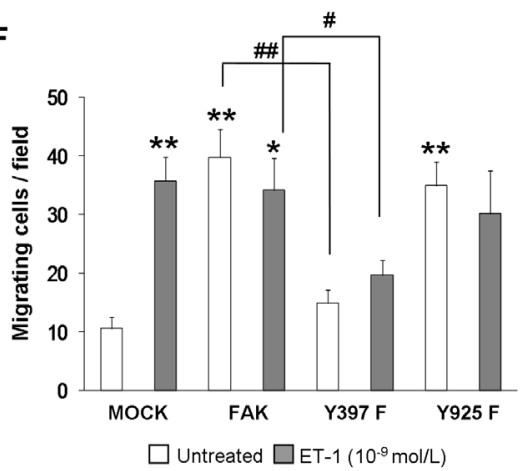

B
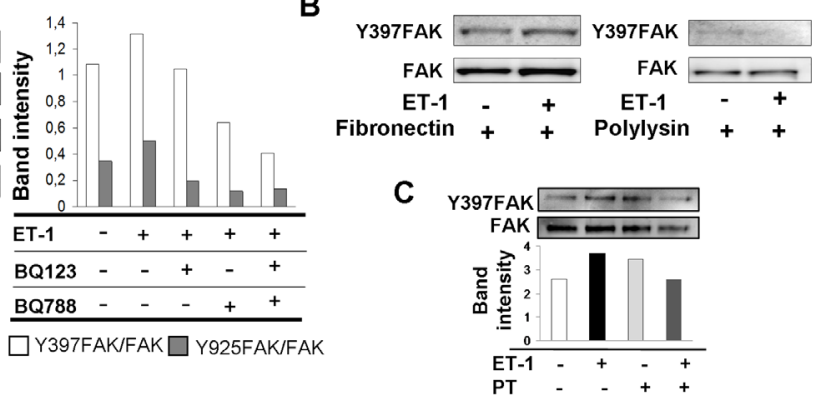

E

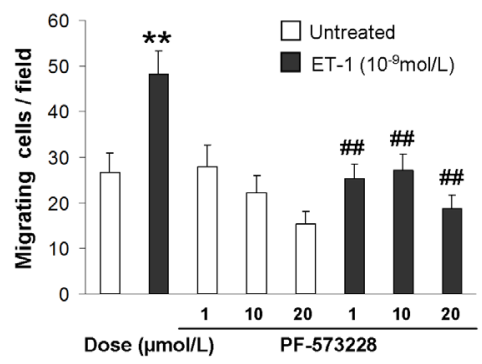

G

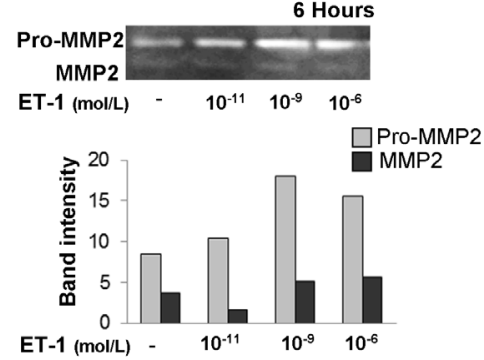

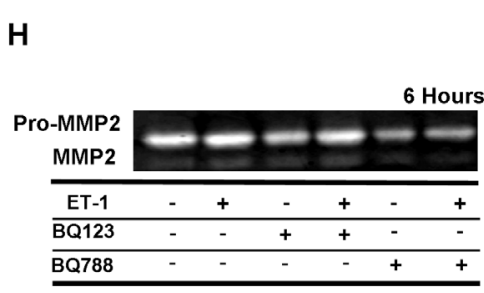

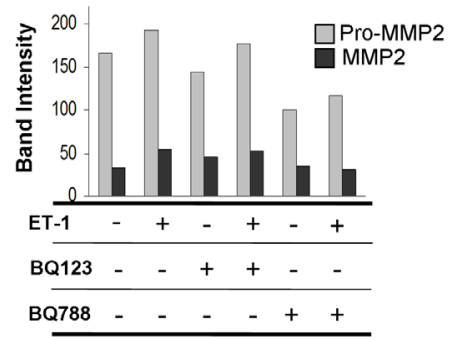

Figure 3 Y397 FAK phosphorylation is essential for ET-1-induced TA-derived VSMC migration. (A) Immunoblot and corresponding quantification of total FAK or FAK phosphorylated at the indicated tyrosine residues in lysates of VSMC cultured for 90 min in the presence or the absence of ET-1 with or without pretreatment with ET-1 receptor antagonist BQ123 or BQ788 at the same concentrations as in previous experiments. (B) Immunoblot and corresponding quantification of $\mathrm{p}$-FAK and total FAK in cell lysates of VSMC seeded on fibronectin $\left(5 \mu \mathrm{g} / \mathrm{cm}^{2}\right)$ or polylysine $(10 \mu \mathrm{g} / \mathrm{mL})$ and cultured for $90 \mathrm{~min}$ in the presence of absence of ET-1 $\left(10^{-9} \mathrm{~mol} / \mathrm{L}\right)$. (C) Immunoblot and corresponding quantification of tyrosine 397 and total FAK from lysates of VSMC cultured for $90 \mathrm{~min}$ with or without ET-1 and with or without previous incubation with PT (1 $\mu \mathrm{g} / \mathrm{mL})$. (D) Immunofluorescence of VSMC $\mathrm{f}$-actin cytoskeleton with phalloidin-rhodamine (red) and nuclei (blue). ET-1 (10 $\left.0^{-9} \mathrm{~mol} / \mathrm{L}\right)$ was added at the time of VSMC seeding. When indicated, VSMCs were preincubated with a FAK inhibitor (PF-573228) at $20 \mu \mathrm{mol} / \mathrm{L}$ for $30 \mathrm{~min}$ before ET-1 exposure. Representative pictures are displayed. (E) Boyden chamber migration assay of VSMC preincubated with increasing concentrations of FAK inhibitor (PF-573228) with or without subsequent addition of ET-1. ${ }^{* *} \mathrm{p}<0.005$ untreated cells versus ET-1-treated cells. \#\#p<0.005 comparing ET-1-treated cells versus ET-1-treated cells preincubated with PF-573228. Cells were counted at 10x magnification. (F) Boyden chamber migration assay of VSMC, 3 days after transfection with empty pcDNA3 vector (MOCK), wild-type FAK (FAK) or FAK mutated at the phosphorylation site Y397F or Y925F. Bars represent the number of migrating cells (mean and SEM) of quadruplicates at $10 \times$ magnification. ${ }^{*} p<0.05{ }^{* *} p<0.005$ untreated cells versus ET-1-treated cells or FAK-transfected cells. $\# p<0.05 / \# \# p<0.005$ for the indicated comparisons. Notice that baseline migration in transfected cells is globally inferior than in non-manipulated cells displayed in figure 2. (G) Gelatin zymography of serum-free supernatants of VSMC cultured in the absence or in the presence of ET-1 for 6 hours. A representative experiment out of three is displayed. $(\mathrm{H})$ Gelatin zymography of serum-free supernatants of VSMC cultured in the presence or in the absence of ET-1 $\left(10^{-9} \mathrm{~mol} / \mathrm{L}\right)$ and ET-1 receptor antagonists BQ123 and BQ788 $(20 \mu \mathrm{mol} / \mathrm{L})$ for 6 hours. A representative experiment out of two is displayed. ET-1, endothelin-1; FAK, focal adhesion kinase; MMP2, matrix metalloproteinase 2; PT, pertussis toxin; TA, temporal arteries; VSMC, vascular smooth muscle cells. 
A
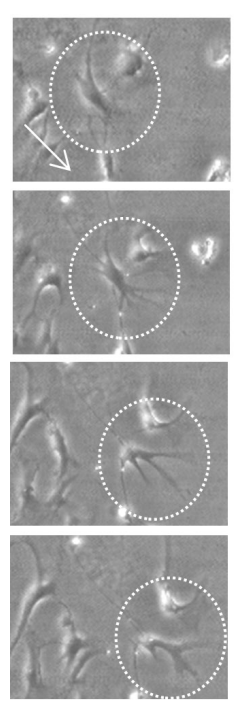

B
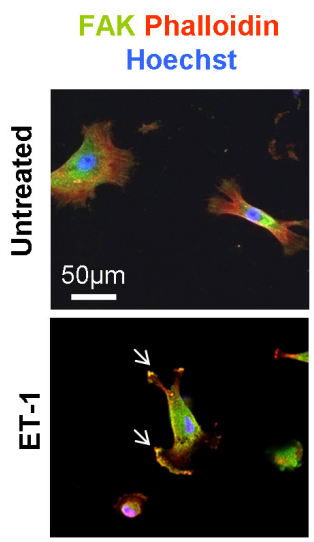

它

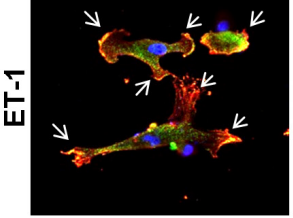

Y397 FAK $\alpha$ SMA

Hoechst

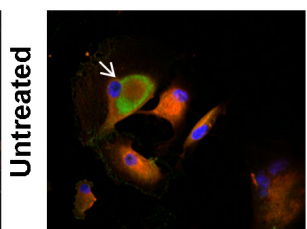

C Untreated
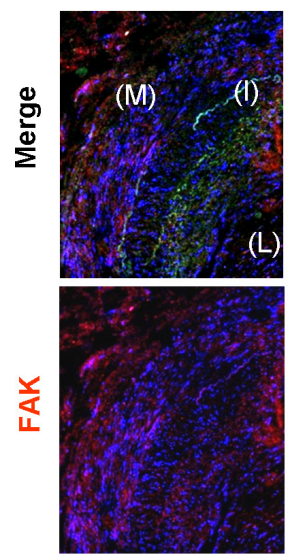

3)

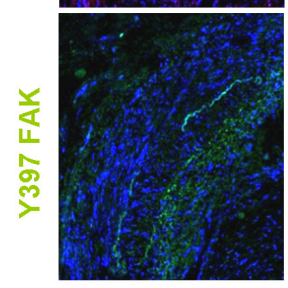

Y397FAK FAK Hoechst

BQ123
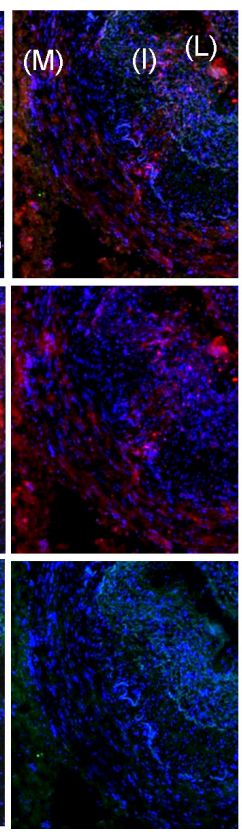

BQ788
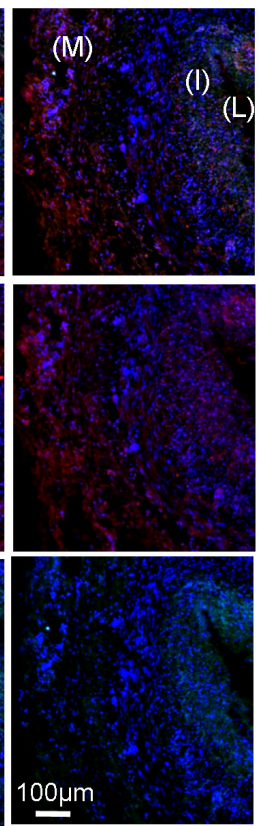

D

Y397FAK FAK Hoechst

Untreated GCA TA

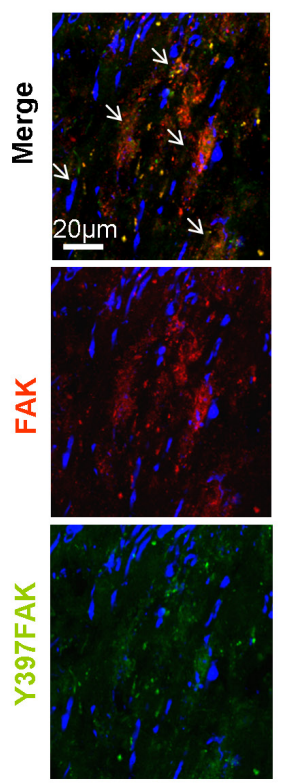

Figure 4 FAK recruitment and phosphorylation at the cell protrusions of ET-1-stimulated VSMC and in ex vivo-cultured TA from patients with GCA. (A) Tracked migratory VSMC exposed to ET-1 (see online supplementary movie). Direction of the migration is indicated by the arrow. (B) Immunofluorescence of total FAK (red) or phospho-Y397 FAK (green), nuclei (blue) and actin cytoskeleton (red) of VSMC cultured in the presence or in the absence of ET-1 $\left(10^{-9} \mathrm{~mol} / \mathrm{L}\right)$ as labelled. Arrows indicate FAK colocalisation with $\alpha$ SMA at the focal adhesions in cell protrusions of migrating cells. (C) Immunofluorescence of pY397 FAK (green), total FAK (red) and nuclei (blue) of a TA from a patient with GCA cultured on Matrigel for 5 days untreated or treated with $\mathrm{ET}_{A} \mathrm{R}$ or $\mathrm{ET}_{B} \mathrm{R}$ antagonist (BQ123 and BQ788, respectively) at $20 \mu \mathrm{mol} / \mathrm{L}$. L, lumen; I, intima layer; $\mathrm{M}$, media layer; $A d v$, adventitia. (D) Magnified VSMC from the media-intima junction of an untreated TA shown in C. Arrow indicates coexpression of phospho-Y397 FAK and total FAK at the media-intima junction of the untreated GCA artery. Separated channels and merge are displayed. Representative picture of multiple cells coexpressing Y397 FAK with FAK. $\alpha$ SMA, $\alpha$-smooth muscle actin; ET-1, endothelin-1; ET $R$, ET-1 receptor A; ET ${ }_{B}$, ET-1 receptor B; FAK, focal adhesion kinase; GCA, giant-cell arteritis; TA, temporal arteries; VSMC, vascular smooth muscle cells.

GCA (figure 6D). Blocking $\mathrm{ET}_{\mathrm{B}} \mathrm{R}$ with BQ788 remarkably inhibited VSMC outgrowth from GCA-involved arteries (figure 6E). The effect of blocking $\mathrm{ET}_{\mathrm{A}} \mathrm{R}$ with BQ123 was less intense but also delayed VSMC outgrowth (figure 6E). Taking together, these data support a seminal role of ET-1 in inducing neointima formation in GCA.

\section{DISCUSSION}

Expression of ET-1 was increased in GCA lesions compared with normal arteries. In GCA, infiltrating leukocytes accounted for the majority of ET-1 expression, which was also enhanced in the luminal endothelium. Some ET-1 expression was also observed in remaining VSMC. Coculture experiments supported that, in an 
A
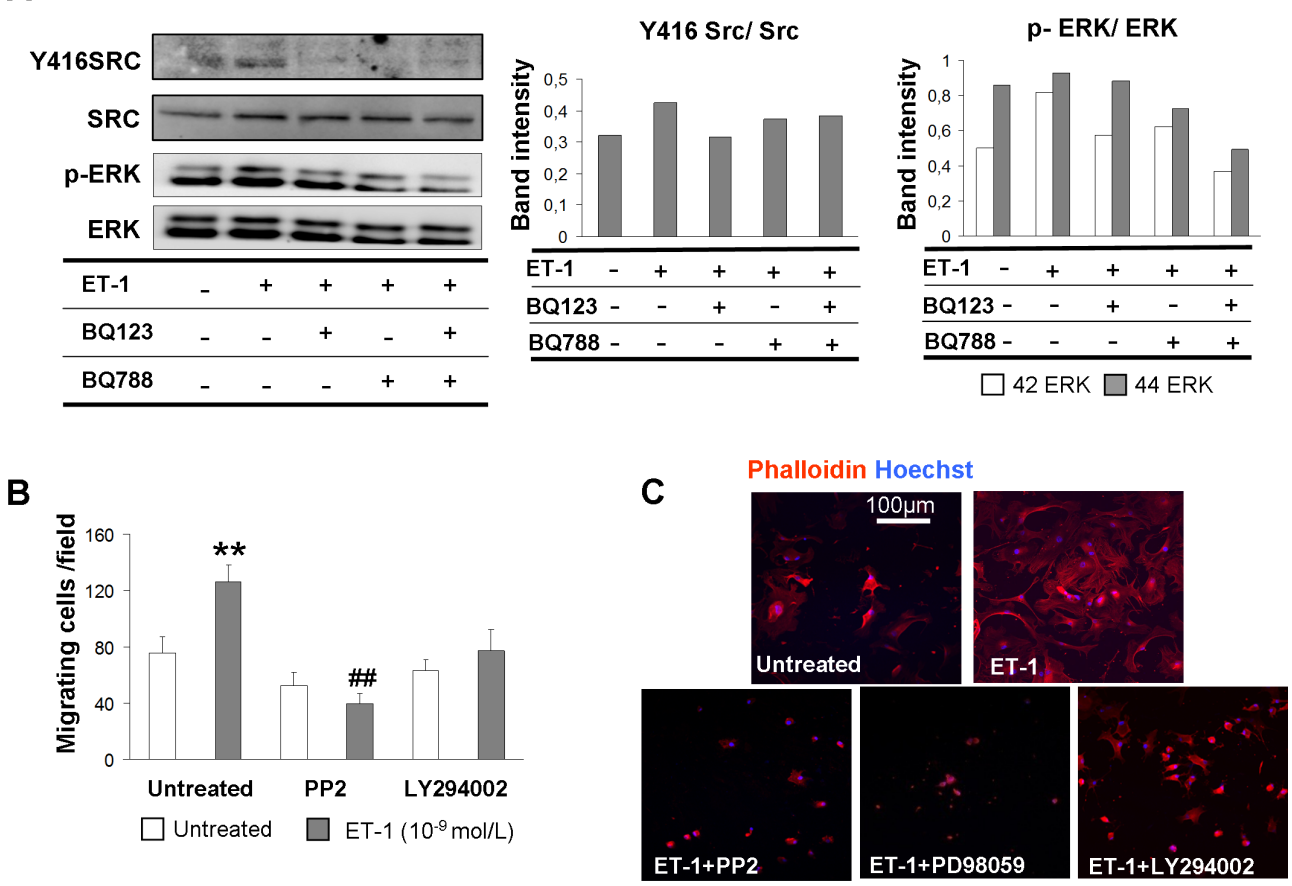

FAK p85 Phalloidin Hoechst
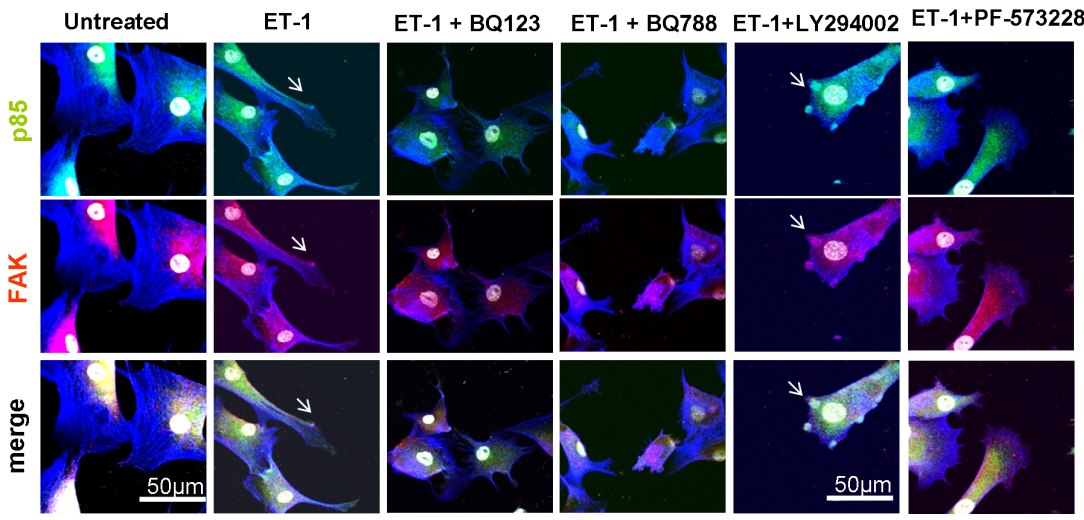

Figure 5 ERK, Src and PI3K participation in ET-1 induced VSMC migration. (A) Immunoblot of phospho-Src (Y416)/total Src and phospho ERK/total ERK in lysates of VSMC treated with ET-1 $\left(10^{-9} \mathrm{~mol} / \mathrm{L}\right)$ for $90 \mathrm{~min}$. Graphs show quantification of a representative experiment out of three independent experiments. (B) VSMC migration in Boyden chambers with or without preincubation with Src inhibitor PP2 (10 $\mu$ mol/L), or PI3K inhibitor LY294002 $(20 \mu \mathrm{mol} / \mathrm{L})$, with or without subsequent addition of ET-1. Bars represent the number of migrated cells (mean and SEM of quadruplicates). * ${ }^{*}<<0.005$ for untreated cells versus ET-1-incubated cells. \#\#p<0.005 for ET-1-treated cells versus VSMC preincubated with inhibitors. (C) Immunofluorescence of VSMC $\mathrm{f}$-actin cytoskeleton (red) and nuclei (blue). ET-1 was added at the time of VSMC seeding. VSMCs were preincubated 30 min in suspension with Src inhibitor (PP2), ERK inhibitor (PD98059) or PI3K inhibitor (LY294002) before addition of ET-1 (10 ${ }^{-9}$ mol/L). Representative pictures of each situation are shown. (D) Immunofluorescence staining of $\mathrm{f}$-actin cytoskeleton (blue), p85 (green), total FAK (red) and nuclei (white) in VSMC treated with ET-1, or ET-1 plus ET R antagonist (BQ123), ET $_{B}$ R antagonist (BQ788), PI3K inhibitor (LY294002) or FAK inhibitor (PF-573228) as labelled. Arrows highlight p85 and FAK colocalisation in the cell protrusions of ET-1-treated VSMC or p85/FAK clusters in immature cell protrusions triggered by ET-1 in the presence of PI3kinase inhibitor LY294002. ET-1, endothelin-1; ET $A$, ET-1 receptor A; ET ${ }_{B} R$, ET-1 receptor B; FAK, focal adhesion kinase; VSMC, vascular smooth muscle cells.

inflammatory microenvironment, ET-1 production is increased in mononuclear cells and decreases in VSMC. ET $\mathrm{R}$ was constitutively expressed by VSMC in normal arteries but, in the context of vascular inflammation, both ET receptors were remarkably increased and expressed by endothelial cells, VSMC and infiltrating leukocytes. As previously reported, the increase in $\mathrm{ET}_{\mathrm{B}} \mathrm{R}$ was much more prominent. ${ }^{17}$

ET-1 stimulated VSMC migration through FAK activation, revealed by ET-1-enhanced FAK autophosphorylation at Y397, creating binding sites for Src kinase and the p85 regulatory subunit of PI3kinase, a crucial process in cell motility. ${ }^{293035}$ ET-1 promoted colocalisation of activated FAK and p85-PI3kinase at the focal adhesions. Subsequent signalling cascades participating in cell motility in other cell types, such as Src and ERK, were also slightly activated. Interestingly, while FAK and Src inhibitors strongly reduced both baseline and ET-1-induced migration, PI3kinase inhibitor selectively inhibited the increase in migration induced by ET-1. Class I PI3kinases are activated by tyrosine kinases whereas class II PI3kinases are activated through GPCR. ${ }^{36} 37$ It is likely that ET-1 promotes activation of both classes of PI3kinases through FAK activation and through GPCR $\mathrm{ET}_{\mathrm{A}} \mathrm{R}$ and $\mathrm{ET}_{\mathrm{B}} \mathrm{R}$. In addition, GPCR-induced heterotrimeric G-protein activation may 
A $\alpha$ SMA-Hoechst
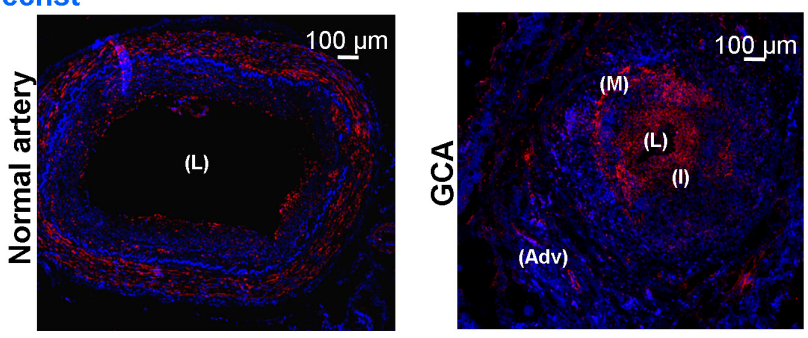

B
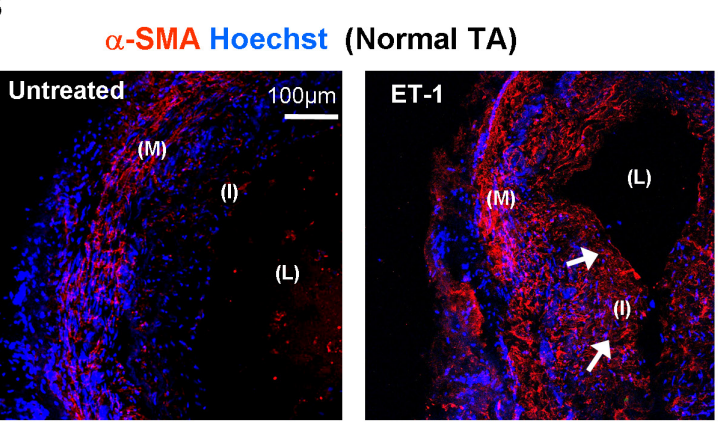

C

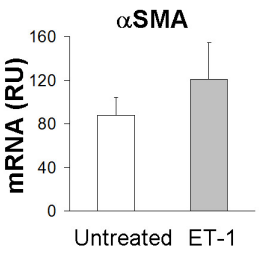

D $\alpha$-SMA Hoechst
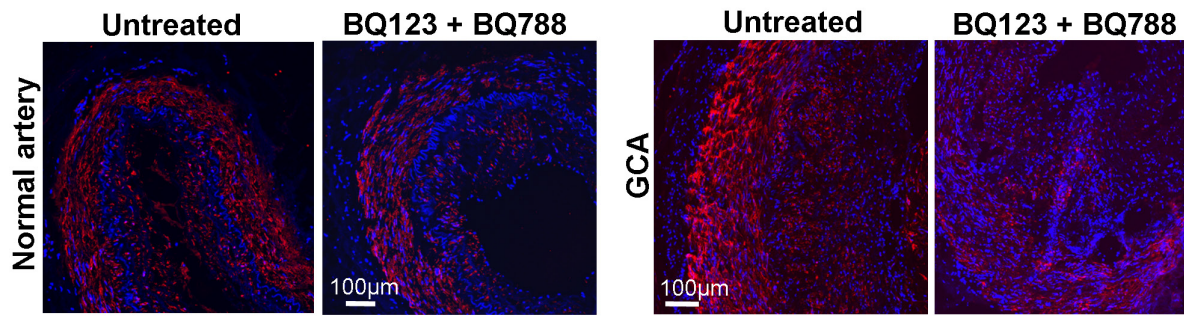

E
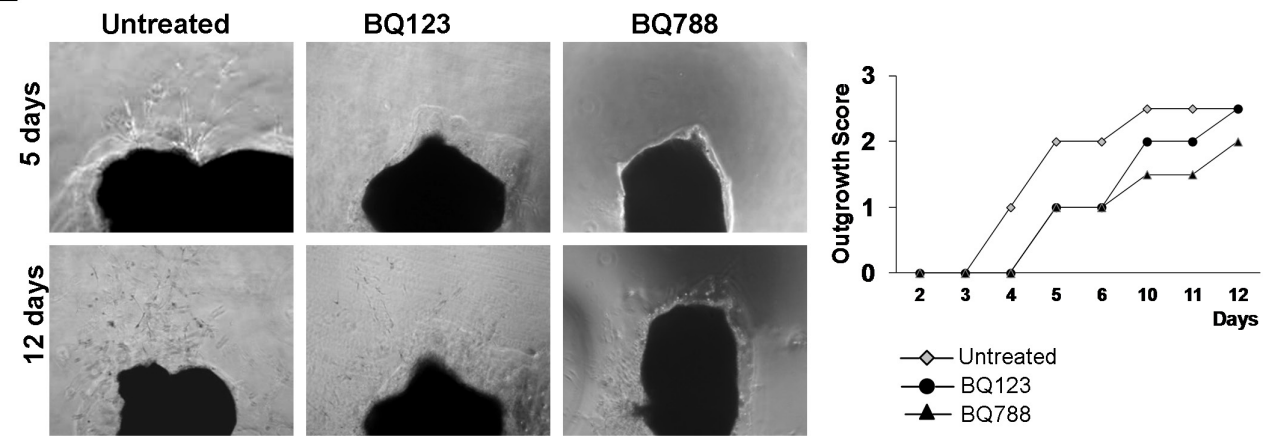

Figure 6 ET-1 induction of VSMC migration in ex vivo TA cultures. (A) Immunofluorescence staining of $\alpha$ SMA (red) and nuclei (blue) in a control TA (left panel) or in a GCA artery with typical lesions (right panel). (B) Immunofluorescence staining of $\alpha$ SMA (red) and nuclei (blue) in a control TA cultured on Matrigel for 5 days in the presence or in the absence of ET- $1\left(10^{-9} \mathrm{~mol} / \mathrm{L}\right)$. Arrows indicate $\alpha \mathrm{SMA}$-positive cells migrating from the media to the intimal layer. Pictures are representative of three different control arteries. L, lumen; I, intimal layer; M, media layer. (C) $\alpha S M A$ mRNA expression in three cultured normal arteries in the absence or in the presence of ET-1 $\left(10^{-9} \mathrm{~mol} / \mathrm{L}\right)$ (upper panel). Immunoblot of $\alpha \mathrm{SMA}$ and $\beta$-actin, with the corresponding quantifications, in a normal TA cultured for 5 days in the absence or in the presence of ET-1 at the same concentration. The experiment was repeated twice with consistent results. (D) Immunofluorescence staining of $\alpha$ SMA (red) and nuclei (blue) in a control TA cultured in Matrigel for 5 days (left panel) and in a GCA-involved artery (right panel) in the presence or absence of ET-1 receptor antagonists (BQ123 and BQ788) at $20 \mu \mathrm{mol} / \mathrm{L}$. (E) VSMC outgrowth from three TAs from patients with GCA cultured on Matrigel for the indicated periods of time with or without the presence of

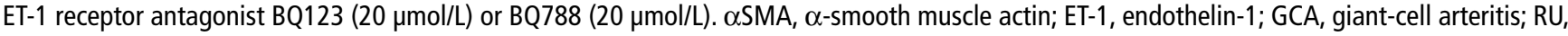
relative units; TA, temporal arteries; VSMC, vascular smooth muscle cells.

also contribute to FAK activation since pertussis toxin abrogated ET-1-induced FAK phosphorylation.

It has been previously shown that FAK coordinates migration with matrix metalloproteinase (MMP) release, which is necessary for cell progression through the extracellular matrix. ${ }^{20}$ ET-1 moderately stimulated release of MMP2 by VSMC, a process mostly mediated by $\mathrm{ET}_{\mathrm{B}} \mathrm{R}$ in our experimental conditions. Since MMP2 has elastinolytic activity, ET-1-induced MMP-2 release may be relevant to the disruption of the internal elastic lamina, characteristically observed 
in GCA lesions, allowing VSMC migration from the muscular to the intimal layer. ${ }^{6} 2138$

FAK has received substantial attention in pathological processes where cell migration is seminal including cancer and fibrosis. ${ }^{1428}$ Our data suggest that FAK is involved in vascular remodelling. Supporting our findings, a recent study has evidenced Y397 phosphorylated FAK in the resistance arteries undergoing vascular remodelling in hypertension. ${ }^{39}$ Selective myeloid deletion of FAK does not influence vascular remodelling in a mouse model, suggesting that expression and activation of FAK in VSMC rather than inflammatory cells may be relevant to vascular occlusion. ${ }^{40}$ Moreover, a naturally occurring truncated form of FAK, FRNK, which acts as competitive inhibitor of FAK, inhibits VSMC invasion in a carotid rat injury model. ${ }^{41}$ Consequently, our results indicate that ET-1-mediated activation of FAK in VSMC may have a seminal role in vascular remodelling in the context of vascular inflammation where ET-1 is mainly produced by inflammatory cells and their production is amplified through interactions with VSMC. These newly recognised functions of ET-1 on VSMC may have a broader impact and may operate in vascular diseases with prominent vascular remodelling beyond GCA. To date, in the field of vascular biology, attention has mainly focused on the vasoconstriction role of ET-1 and only responses related to vascular reactivity or hypertension have been explored after conditional deletion of $\mathrm{ET}_{\mathrm{A}} \mathrm{R}$ in VSMC. ${ }^{1041}$ In a pioneer study performed in mice more than one decade ago, induced overexpression of ET-1 in endothelial cells resulted in increased vascular remodelling. ${ }^{42}$ However, this interesting observation has not been further explored.

Based on its presumed major function, ET-1 has been considered a therapeutic target for vascular diseases where vasoconstriction is thought to play a major role such as systemic or pulmonary hypertension or, more recently, fibrotic diseases, such as scleroderma or lung fibrosis, according to the newly recognised functions of ET-1 on fibroblasts. ${ }^{9} 101314$ However, to date, clinical trials with ET-1 receptor antagonists have shown the best efficacy for diseases with prominent vascular remodelling such as ischaemic ulcers in systemic sclerosis or pulmonary hypertension rather than vasoconstriction or fibrotic diseases. 91043

There is an unmet need of treatments reducing inflammation-induced vascular remodelling in GCA since patients with systemic vasculitis may develop complications derived from vascular occlusion in spite of glucocorticoid or immunosuppressive therapy. ${ }^{44}$ Our data underline an unprecedented and crucial role for ET-1 in inducing vascular remodelling and vascular occlusion in the context of vascular inflammation and point towards endothelin receptor antagonists as potential therapeutic targets to avoid maladaptive vascular remodelling in inflammatory diseases of blood vessels.

Acknowledgements The authors would like to thank Dr Ester Sánchez-Tillo for helping with plasmid production and Ester Tobias for the technical support in processing TA biopsies for immunofluorescence. We thank Anna Bosch, Elisenda Coll and Maria Calvo from the Advanced Optical Microscopy department of the University of Barcelona for their support with confocal microscopy. We also thank Jara Palomero and Marta L Rodríguez from the group of Virgina Amador for their help and input in various aspects. We thank K Matsumoto and KM Yamada ( $\mathrm{NIH}$, Bethesda, Maryland) for providing FAK mutants.

Contributors $M C C$ and EPR designed the experiments and wrote the manuscript. EPR, NTG and MCB performed the experimental work. EL and MS contributed preliminary results essential for the development of the study. MAA, GEF, SPG and JHR contributed to clinical selection and TA biopsy collection. SP and RL produced and provided BQ123. All authors read, made improvements and approved the final version.
Funding This study was supported by the Ministerio de Economía y Competitividad (SAF 14/57708-R, Marató TV3 2014/ 20150730) and Instituto de Salud Carlos III (PIE13/00033), both cofunded by Fondo Europeo de Desarrollo Regional (FEDER), Unión Europea, una manera de hacer Europa. SP and RL were supported by DGICYT-Spain (CTQ2015-67870-P) and Generalitat de Catalunya (2014 SGR 137).

Competing interests None declared.

Patient consent Obtained.

Ethics approval Ethics Committee Hospital Clinic of Barcelona.

Provenance and peer review Not commissioned; externally peer reviewed.

(c) Article author(s) (or their employer(s) unless otherwise stated in the text of the article) 2017. All rights reserved. No commercial use is permitted unless otherwise expressly granted.

\section{REFERENCES}

1 Jennette JC, Falk RJ, Bacon PA, et al. Revised international chapel Hill consensus conference nomenclature of Vasculitides. Arthritis Rheum 2012;2013:1-11.

2 Salvarani C, Pipitone N, Versari A, et al. Clinical features of polymyalgia rheumatica and giant cell arteritis. Nat Rev Rheumato/ 2012;8:509-21.

3 Font C, Cid MC, Coll-Vinent B, et al. Clinical features in patients with permanent visual loss due to biopsy-proven giant cell arteritis. Br J Rheumato/ 1997;36:251-4.

4 Salvarani C, Cimino L, Macchioni P, et al. Risk factors for visual loss in an italian population-based cohort of patients with giant cell arteritis. Arthritis Rheum 2005; 53:293-7

5 Cid MC, Font C, Oristrell J, et al. Association between strong inflammatory response and low risk of developing visual loss and other cranial ischemic complications in giant cell (temporal) arteritis. Arthritis Rheum 1998;41:26-32.

6 Hernández-Rodríguez J, Murgia G, Villar I, et al. Description and validation of histological patterns and proposal of a Dynamic Model of inflammatory infiltration in Giant-cell arteritis. Medicine 2016;95:e2368.

7 Lozano E, Segarra M, García-Martínez A, et al. Imatinib mesylate inhibits in vitro and ex vivo biological responses related to vascular occlusion in giant cell arteritis. Ann Rheum Dis 2008;67:1581-8.

8 Ly KH, Régent A, Molina E, et al. Neurotrophins are expressed in giant cell arteritis lesions and may contribute to vascular remodeling. Arthritis Res Ther 2014;16:487

9 Rodríguez-Pascual F, Busnadiego 0, Lagares D, et al. Role of endothelin in the cardiovascular system. Pharmacol Res 2011;63:463-72.

10 Davenport AP, Hyndman KA, Dhaun N, et al. Endothelin. Pharmacol Rev 2016;68:357-418.

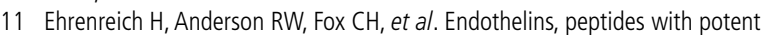
vasoactive properties, are produced by human macrophages. J Exp Med 1990:172:1741-8.

12 Horinouchi T, Terada K, Higashi T, et al. Endothelin receptor signaling: new insight into its regulatory mechanisms. J Pharmaco/ Sci 2013;123:85-101.

13 Lagares D, García-Fernández RA, Jiménez $C L$, et al. Endothelin 1 contributes to the effect of transforming growth factor beta 1 on wound repair and skin fibrosis. Arthritis Rheum 2010:62:878-89.

14 Lagares D, Busnadiego 0, García-Fernández RA, et al. Adenoviral gene transfer of endothelin-1 in the lung induces pulmonary fibrosis through the activation of focal adhesion kinase. Am J Respir Cell Mol Biol 2012;47:834-42.

15 Leask A. Potential therapeutic targets for cardiac fibrosis: tgfbeta, angiotensin, endothelin, CCN2, and PDGF, partners in fibroblast activation. Circ Res 2010;106:1675-80.

16 Visvanathan S, Rahman MU, Hoffman GS, et al. Tissue and serum markers of inflammation during the follow-up of patients with giant-cell arteritis--a prospective longitudinal study. Rheumatology 2011;50:2061-70.

17 Dimitrijevic I, Andersson C, Rissler P, et al. Increased tissue endothelin-1 and endothelin-B receptor expression in temporal arteries from patients with giant cell arteritis. Ophthalmology 2010;117:628-36.

18 Lozano E, Segarra M, Corbera-Bellalta M, et al. Increased expression of the endothelin system in arterial lesions from patients with giant-cell arteritis: association between elevated plasma endothelin levels and the development of ischaemic events. Ann Rheum Dis 2010;69:434-42.

19 Corbera-Bellalta M, Planas-Rigol E, Lozano E, et al. Blocking interferon $\gamma$ reduces expression of chemokines CXCL9, CXCL10 and CXCL11 and decreases macrophage infiltration in ex vivo cultured arteries from patients with giant cell arteritis. Ann Rheum Dis 2016;75:1177-86.

20 Segarra M, Vilardell C, Matsumoto K, et al. Dual function of focal adhesion kinase in regulating integrin-induced MMP-2 and MMP-9 release by human T lymphoid cells. Faseb J 2005;19:1875-7.

21 Segarra M, García-Martínez A, Sánchez M, et al. Gelatinase expression and proteolytic activity in giant-cell arteritis. Ann Rheum Dis 2007;66:1429-35.

22 Tamura M, Gu J, Danen EH, et al. PTEN interactions with focal adhesion kinase and suppression of the extracellular matrix-dependent phosphatidylinositol 3-kinase/Akt cell survival pathway. J Biol Chem 1999;274:20693-703. 
23 Corbera-Bellalta M, García-Martínez A, Lozano E, et al. Changes in biomarkers after therapeutic intervention in temporal arteries cultured in Matrigel: a new model for preclinical studies in giant-cell arteritis. Ann Rheum Dis 2014;73:616-23.

24 Cid MC, Campo E, Ercilla G, et al. Immunohistochemical analysis of lymphoid and macrophage cell subsets and their immunologic activation markers in temporal arteritis. influence of corticosteroid treatment. Arthritis Rheum 1989;32:884-93.

25 Cid MC, Esparza J, Schnaper HW, et al. Estradiol enhances endothelial cell interactions with extracellular matrix proteins via an increase in integrin expression and function. Angiogenesis 1999;3:271-80.

26 Schaller MD, Parsons JT. Focal adhesion kinase and associated proteins. Curr Opin Cell Biol 1994;6:705-10.

27 Mitra SK, Hanson DA, Schlaepfer DD. Focal adhesion kinase: in command and control of cell motility. Nat Rev Mol Cell Biol 2005;6:56-68.

28 Sulzmaier FJ, Jean C, Schlaepfer DD. FAK in Cancer: mechanistic findings and clinical applications. Nat Rev Cancer 2014;14:598-610.

29 Schaller MD, Hildebrand JD, Shannon JD, et al. Autophosphorylation of the focal adhesion kinase, pp125FAK, directs SH2-dependent binding of pp60src. Mol Cell Biol 1994;14:1680-8.

30 Schlaepfer DD, Hunter T. Evidence for in vivo phosphorylation of the Grb2 SH2domain binding site on focal adhesion kinase by Src-family protein-tyrosine kinases. Mol Cell Biol 1996;16:5623-33.

31 Shen B, Delaney MK, Du X. Inside-out, outside-in, and inside-outside-in: $g$ protein signaling in integrin-mediated cell adhesion, spreading, and retraction. Curr Opin Cell Biol 2012;24:600-6.

32 Kehrl JH. The impact of RGS and other G-protein regulatory proteins on Goimediated signaling in immunity. Biochem Pharmacol 2016;114:40-52.

33 Esparza J, Vilardell C, Calvo J, et al. Fibronectin upregulates gelatinase B (MMP-9) and induces coordinated expression of gelatinase A (MMP-2) and its activator MT1MMP (MMP-14) by human T lymphocyte cell lines. A process repressed through RAS/ MAP kinase signaling pathways. Blood 1999;94:2754-66.
34 Parsons JT, Horwitz AR, Schwartz MA. Cell adhesion: integrating cytoskeletal cell migration: integrating signals from front to back. Nat Rev Mol Cell Biol 2010;11:633-.

35 Chen HC, Appeddu PA, Isoda H, et al. Phosphorylation of tyrosine 397 in focal adhesion kinase is required for binding phosphatidylinositol 3-kinase. J Biol Chem 1996;271:26329-34.

36 Reiske HR, Kao SC, Cary LA, et al. Requirement of phosphatidylinositol 3-kinase in focal adhesion kinase-promoted cell migration. J Biol Chem 1999;274:12361-6.

37 Shi-Wen X, Chen Y, Denton CP, et al. Endothelin-1 promotes myofibroblast induction through the ETA receptor via a rac/phosphoinositide 3-kinase/Akt-dependent pathway and is essential for the enhanced contractile phenotype of fibrotic fibroblasts. Mol Biol Cell 2004;15:2707-19.

38 Planas Rigol E, Corbera Bellalta M, et al. Giant-Cell Arteritis: immunopathogenic mechanisms involved in vascular inflammation and remodeling. Journal of Vasculitis 2016;2:1-7.

39 Heerkens EH, Quinn L, Withers SB, et al. $\beta$ integrins mediate FAK Y397 autophosphorylation of resistance arteries during eutrophic inward remodeling in hypertension. J Vasc Res 2014;51:305-14.

40 Heuslein JL, Murrell KP, Leiphart RJ, et al. Vascular growth responses to chronic arterial occlusion are unaffected by myeloid specific focal adhesion kinase (FAK) deletion. Sci Rep 2016;6:27029.

41 Donato AJ, Lesniewski LA, Stuart D, et al. Smooth muscle specific disruption of the endothelin-A receptor in mice reduces arterial pressure, and vascular reactivity and affects vascular development. Life Sci 2014;118:238-43.

42 Amiri F, Virdis A, Neves MF, et al. Endothelium-restricted overexpression of human endothelin-1 causes vascular remodeling and endothelial dysfunction. Circulation 2004;110:2233-40.

43 Rodríguez-Pascual F, Busnadiego 0, González-Santamaría J. The profibrotic role of endothelin-1: is the door still open for the treatment of fibrotic diseases? Life Sci 2014;118:156-64.

44 Cid MC, García-Martínez A, Lozano E, et al. Five clinical conundrums in the management of giant cell arteritis. Rheum Dis Clin North Am 2007;33:819-34. 
ARD Endothelin-1 promotes vascular smooth muscle cell migration across the artery wall: a mechanism contributing to vascular remodelling and intimal hyperplasia in giant-cell arteritis

Ester Planas-Rigol, Nekane Terrades-Garcia, Marc Corbera-Bellalta, Ester Lozano, Marco A Alba, Marta Segarra, Georgina Espígol-Frigolé, Sergio Prieto-González, José Hernández-Rodríguez, Sara Preciado, Rodolfo Lavilla and Maria C Cid

Ann Rheum Dis published online June 12, 2017

Updated information and services can be found at:

http://ard.bmj.com/content/early/2017/06/12/annrheumdis-2016-2107 92

These include:

References This article cites 44 articles, 17 of which you can access for free at: http://ard.bmj.com/content/early/2017/06/12/annrheumdis-2016-2107 92\#ref-list-1

Email alerting

Receive free email alerts when new articles cite this article. Sign up in the service box at the top right corner of the online article.

\section{Notes}

To request permissions go to:

http://group.bmj.com/group/rights-licensing/permissions

To order reprints go to:

http://journals.bmj.com/cgi/reprintform

To subscribe to BMJ go to:

http://group.bmj.com/subscribe/ 